\title{
Metabolic Myopathy
}

National Cancer Institute

\section{Source}

National Cancer Institute. Metabolic Myopathy. NCI Thesaurus. Code C98985.

A group of rare inherited disorders characterized by a deficiency of enzymes that are involved in metabolic pathways that affect muscles. The disorders are characterized by muscle dysfunction. 